\title{
Antibiotic impregnated tablets for screening ESBL and AmpC beta lactamases
}

\author{
Ritu Nayar, Vivek Mohan Arora, Shalini Duggal \\ Department of Microbiology, \\ Dr Baba Saheb Ambedkar Hospital \\ Rohini, New Delhi
}

\begin{abstract}
:
Antibiotic resistance is a growing threat. Fifty non repetitive multi drug resistant gram negative bacterial isolates were screened for ESBL, AmpC, ESBL-AmpC co-production using antibiotic tablets. Of these 56\% were Escherichia coli, 16\% were Klebsiella spp., 39.6\% produced ESBLs, $17.2 \%$ AmpC and 13.8\% showed co-production. Antibiotic tablets sensitivity for ESBL detection was $93.9 \%$ compared to filter paper discs. We emphasize that even small and medium level laboratories should screen for ESBL and AmpC production to check the burden of antibiotic resistance. Use of antibiotic tablets, though costlier can be used especially in tropical countries given their stability during transit from manufacturer to user.
\end{abstract}

Key words: ESBL, AmpC, antibiotic impregnated tablets

\section{INTRODUCTION}

Antimicrobial drug resistance is of growing concern. Surveillance studies provide important information about changes in microbial spectrum and trends in antimicrobial resistance patterns. An increase in prevalence of extended spectrum beta lactamases (ESBLs) and AmpC beta lactamases worldwide creates a need for effective and easy to perform screening methods for detection. Antibiotic sensitivity tablet is one such tool where antimicrobial agents are in readily diffusible and stable form. The present study was done to screen for AmpC and ESBL producing gram negative bacilli among clinical isolates in our hospital by use of antibiotic tablets (Neosensitabs ${ }^{\mathrm{TM}}$ ).

\section{MATERIAL \& METHODS}

The study comprised of clinical specimens received for bacteriological processing from different wards. These included urine, blood, pus, respiratory specimens, etc. from patients in sterile containers. Of 527 consecutive samples, 50 non repetitive multi drug resistant (MDR) gram negative bacterial isolates were included. We considered an isolate MDR if it was resistant to aminoglycoside, fluoroquinolone and third generation cephalosporin tested. Identification was by standard bacteriological tests ${ }^{[1]}$ and antibiotic susceptibility testing was performed by Kirby Bauer disk diffusion method following

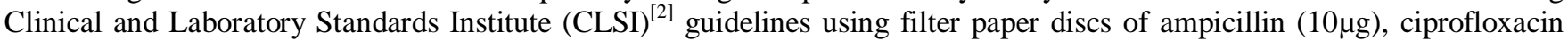
$(5 \mu \mathrm{g})$, gentamicin $(10 \mu \mathrm{g})$, ceftriaxone $(30 \mu \mathrm{g})$, amoxycillin-clavulanic acid $(20 / 10 \mu \mathrm{g})$ and trimethoprim-sulfamethoxazole $(1.25 / 23.75 \mu \mathrm{g})$ (Hi-media). Escherichia coli ATCC 25922 and Klebsiella pneumoniae ATCC 700603 were used as negative and positive controls respectively for ESBL production. For phenotypic screening of ESBL and AmpC production, NeoSensitab $^{\mathrm{TM}}$ (RoscoDiagnostica, Denmark) were used which included antibiotic impregnated tablets, $9 \mathrm{~mm}$ in size producing

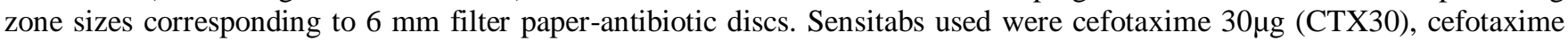

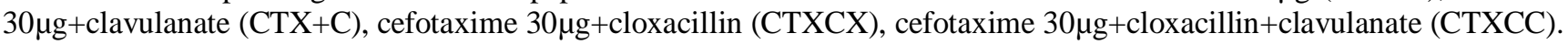

By measuring differences in zone of inhibition, they were categorized into strains which produced ESBL or AmpC or both. The results were interpreted as follows:

\begin{tabular}{|ccccc|}
\hline $\begin{array}{c}\text { RESISTANCE } \\
\text { MARKER }\end{array}$ & CTX30 & CTX+C & CTXCX \\
\hline ESBL & CTX+C or CTXCC & $\geq 5 \mathrm{~mm}$ & - & - \\
\hline \multirow{2}{*}{ AmpC } & CTXCX or CTXCC & $\geq 5 \mathrm{~mm}$ & $<5 \mathrm{~mm}$ & $\geq 5 \mathrm{~mm}$ \\
\hline
\end{tabular}




\begin{tabular}{|lccccc|}
\hline ESBL+AmpC & CTX+C\& CTXCC & $<5 \mathrm{~mm}$ & - & - \\
& & - & $\geq 5 \mathrm{~mm}(\mathrm{AmpC})$ & $\geq 5 \mathrm{~mm}(\mathrm{ESBL})$ \\
\hline
\end{tabular}

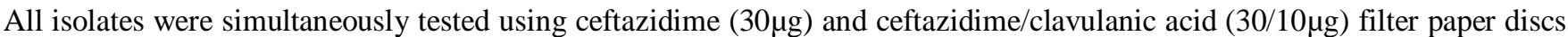
(Hi Media). Isolates showing difference of $\geq 5 \mathrm{~mm}$ were interpreted as positive for ESBL production ${ }^{21}$. This method was treated as standard for purpose of comparison.

\section{RESULTS}

Total 527 specimens were received in the Microbiology laboratory during study period of which 116 showed growth of clinically significant gram negative bacteria including 50 multidrug resistant isolates. Of MDR isolates, $22 \%$ were obtained from OPD while 78\% from in-patients including ICU, wards and nursery. Escherichia coli was isolated in 28 followed by Klebsiella spp. in 8, Enterobacter spp. in 6, Acinetobacter spp and Proteus spp. in 3 specimens each while Morganella spp and Citrobacter spp. in one each. Resistance to ampicillin, ciprofloxacin, gentamicin, ceftriaxone, amoxycillin-clavulanic acid and trimethoprim-sulfamethoxazole was found to be $98 \%, 64 \%, 54 \%, 92 \%, 82 \%$ and $72 \%$ respectively. The isolates were classified as ESBL producers, AmpC producers and both i.e. co-producers (Table 1) based on aforementioned criteria. Among 50 MDR isolates, Neo-sensitabs detected 46 ESBLs producing isolates while using ceftazidime and ceftazidime + clavulanic acid filter paper discs, 49 isolates were detected to produce ESBLs. Thus sensitivity of Neo-sensitabs compared to disc diffusion method for screening ESBLs was 93.9\%.

Table 1: Distribution of Extended spectrum (ESBL) and AmpC beta lactamases and Co-producers using antibiotic tablets

\begin{tabular}{|c|c|c|}
\hline \multicolumn{3}{|l|}{ antibiotic tab } \\
\hline ESBL PRODUCERS & 46 & $39.6 \%$ \\
\hline AMP C PRODUCERS & 20 & $17.2 \%$ \\
\hline ESBL +ve AMP C -ve & 30 & $25.8 \%$ \\
\hline ESBL -ve AMP C +ve & 04 & $3.4 \%$ \\
\hline CO-PRODUCERS & 16 & $13.8 \%$ \\
\hline TOTAL MDR ISOLATES & 50 & $43.1 \%$ \\
\hline
\end{tabular}

Legend for Figure 1: An isolate showing ESBL and AmpC coproduction

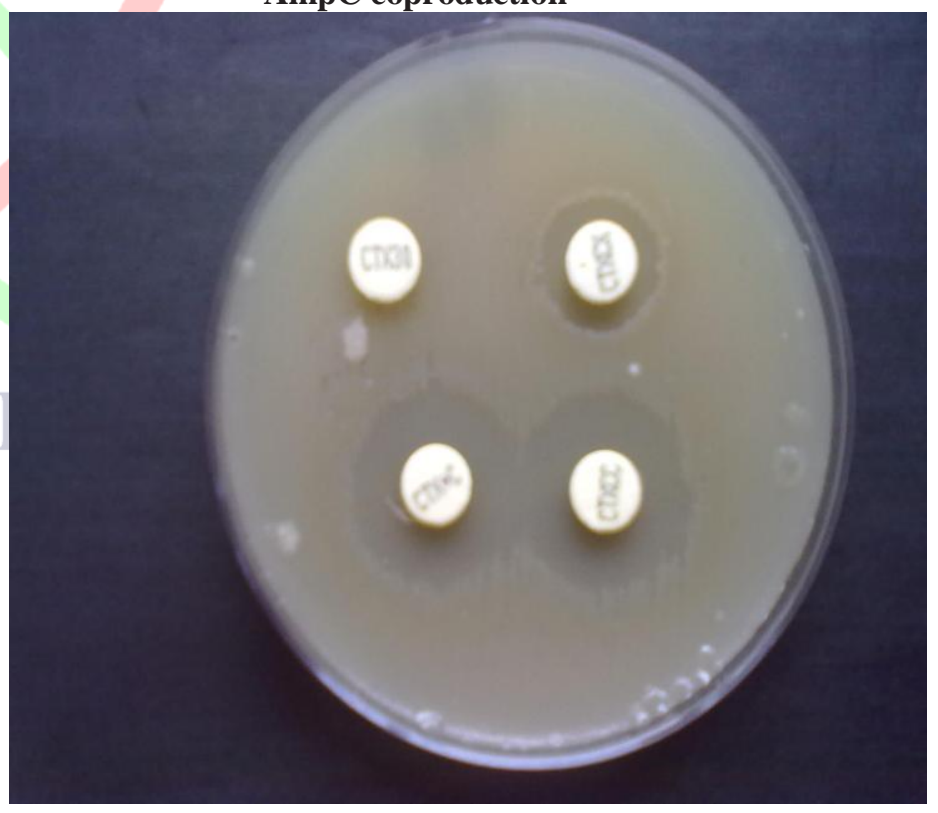

\section{DISCUSSION}

Extended-spectrum $\beta$ lactamases (ESBLs) are rapidly evolving $\beta$ lactamases which are capable of conferring bacterial resistance to penicillins; first, second, third generation cephalosporins; and aztreonam (but not the cephamycins or carbapenems) by hydrolysis of these antibiotics ${ }^{[3]}$. Clavulanic acid can be used as $\beta$ lactamase inhibitor to screen for ESBL production. However their use for treatment of ESBL producing bacteria is not encouraged because of possibility of inoculum effect ${ }^{[4]}$. Prevalence of ESBL in present study was found to be $39.6 \%$ (46/116). Agarwal et al ${ }^{[5]}$ and Singhal et al ${ }^{[6]}$ have reported $22 \%$ and $64 \%$ incidence of ESBLs at their centers respectively. 
Other emerging resistance mechanisms such as AmpC enzymes and metallo beta lactamases are also being increasingly seen in members of family Enterobacteriaceae. AmpC $\beta$ lactamases are cephalosporinases which are either not inhibited, or poorly inhibited by clavulanic acid. Their ability to hydrolyse cephamycins and extended spectrum cephalosporins differentiate them from $\mathrm{ESBLs}^{[7]}$. Amp C $\beta$ lactamases are either plasmid mediated or chromosomally mediated/inducible, chromosomal AmpC enzymes are seen in organisms such as Citrobacter freundii, Enterobacter cloacae, Morganella morganii, Hafnia alvei and Serratia marcescens. These are typically inducible by $\beta$-lactam antibiotics such as cefoxitin and imipenem ${ }^{[8]}$. In our study $3.4 \%$ of the isolates were seen to produce pure AmpC $\beta$ lactamase similar to study by Hemlatha et $\mathrm{al}^{[9]}$ who reported a prevalence of $9.2 \%$ among E.coli and Klebsiella spp. In this study overall Amp C prevalence was $17.2 \%$ compared to two studies from Chennai reporting $27 \%^{[10]}$ and $47.3 \%{ }^{[9]}$ whereas two other studies have reported $8 \%{ }^{[6]}$ and $25.5 \%{ }^{[11]}$ Amp C production among members of Enterobacteriaceae. This variation can be attributed to regional variation, antibiotic usage, sensitivity pattern among a wide variety of other causes. Co existence of both AmpC BL and ESBL in Gram negative organisms could be due to dissemination of plasmid mediated AmpC beta lactamases among members of family Enterobacteriaceae, sometimes in combination with ESBLs ${ }^{[6]}$. In the present study, $13.8 \%(16 / 116)$ isolates were found to produce both ESBL and AmpC beta lactamases, similar to study by Sinha et $\mathrm{al}^{[12]}$ who reported $8 \%$ co-production among $E$. coli. As compared to disc diffusion method, sensitivity of antibiotic tablets in our study was $93.9 \%$. Though they cost more, they have the advantage of greater stability and shelf life over antibiotic impregnated filter paper discs ${ }^{[13]}$ which is pertinent for a country like ours where maintenance of cold chain is a major issue. An additional advantage is that these tablets can also be utilized for agar dilution methods. To conclude, resistance against commonly used antibiotics for treatment of different infections is increasing day by day. Hence monitored and judicious use of such drugs should be encouraged and use of empiric antibiotics should be discouraged. The prevalence of ESBL and AmpC producing bacteria was found to be low in our hospital setting as compared to other hospitals. Routine screening for these resistance mechanisms should be instituted even in small/medium level laboratories to control spread of infections by these microorganisms. Sensitivity tablets as well as antibiotic impregnated discs can be used for this purpose. As WHO puts it 'No Action Today No Cure Tomorrow', control measures like judicious use of antibiotics, strict hand hygiene and protocols for implementation of infection control strategies in every hospital should be encouraged.

Acknowledgement: Bhawna Nohwal, B. Tech. Biotechnology Student, Maharishi Markandeshwar University, Mullana Ambala, Haryana for scientific data analysis and Mr. Javed Ahmed Genetix Biotech Asia(P) Ltd., for providing antibiotic tablets for study.

\section{REFERENCES}

[1]. Collee JG, Miles RS, Watt B. Tests for identification of bacteria. In: Mackie and McCartney Practical Medical Microbiology, 14th ed. Collee JG, Fraser AG, Marmion BP, Simmons A, editors. (Churchil Livingstone: New York) 1996.p.131-49.

[2]. Clinical Laboratory Standards Institute. Performance Standards for Antimicrobial Susceptibility Testing; Twenty first Informational Supplement. CLSI document M100-S21. Wayne, PA: Clinical Laboratory Standards Institute, 2011.

[3]. Bush K, Jacoby GA, Medeiros AA. A functional classification scheme for $\beta$-lactamases and its correlation with molecular structure. Antimicrob Agents Chemother, 1995;39:1211-33.

[4]. Koneman EW, Allen SD, Janda WM, Schreckenberger PC, Win WC, editors. Antimicrobial Susceptibility Testing. In: Color atlas and textbook of diagnostic microbiology, $6^{\text {th }}$ ed. JB Lippincott Co: Philadelphia; 2006. p.945-1021.

[5]. Agarwal P, Ghosh AN, Kumar S, Basu B, Kapila K. Prevalence of extended spectrum beta lactamases among Escherichia coli \& Klebsiella pneumoniae isolates in a tertiary care hospital. Indian J Pathol Microbiol, 2008;51:139-42.

[6]. Singhal S, Mathur T, Khan S, Upadhyay DJ, Chugh S, Gaind R, et al. Evaluation of methods for AmpC beta-lactamase in Gram negative clinical isolates from tertiary care hospitals. Indian J Med Microbiol, 2005;23:120-4.

[7]. Manchanda V, Singh NP. Occurrence and detection of AmpC $\beta$ lactamases among Gram negative clinical isolates using a modified three dimensional test at Guru Teg Bahadur Hospital, Delhi, India. J Antimicrob Chemother, 2003;51:415-8.

[8]. Philippon A, Arlet G, Jacoby GA. Plasmid-determined AmpC type beta lactamases. Antimicrob Agents Chemother, 2002;46:1-11. 
[9]. Hemalatha V, Padma M, Sekar U, Vinodh TM, Arunkumar AS. Detection of Amp C beta lactamases production in Escherichia coli \& Klebsiella by an inhibitor based method. Indian J Med Res, 2007;126:220-3.

[10]. Subha A, Devi VR, Ananthan S. AmpC beta-lactamase producing multidrug resistant strains of Klebsiella spp. and Escherichia coli isolated from children under five in Chennai. Indian J Med Res, 2003;117:13-8.

[11]. Manchanda V, Singh NP, Shamweel A, Eideh HK, Thukral SS. Molecular epidemiology of clinical isolates of AmpC producing Klebsiella pneumoniae. Indian J Med Microbiol, 2006;24:177-81.

[12]. Sinha P, Sharma R, Rishi S, Sharma R, Sood S, Pathak D. Prevalence of extended spectrum beta lactamase and AmpC beta lactamase producers among Escherichia coli isolates in a tertiary care hospital in Jaipur. Indian J Pathol Microbiol, 2008;51:367-9.

[13]. Brown DFG, Kothari D. Comparison of tablets and paper discs for antibiotic sensitivity testing. J Clin Path, 1975;28:983-8. 